\title{
Neonatal and young infant sepsis by Group B Streptococci and Escherichia coli: a single-center retrospective analysis in Germany-GBS screening implementation gaps and reduction in antibiotic resistance
}

\author{
Maren Doenhardt ${ }^{1}$ (D) Barbara Seipolt ${ }^{1} \cdot$ Lars Mense $^{1} \cdot$ Jennifer Lucia Winkler $^{2} \cdot$ Alexander Thürmer $^{3}$. \\ Mario Rüdiger $^{1} \cdot$ Reinhard Berner $^{1}$ - Jakob Armann ${ }^{1}$
}

Received: 15 January 2020 / Revised: 24 March 2020 / Accepted: 22 April 2020 / Published online: 23 May 2020

(C) The Author(s) 2020

\begin{abstract}
The last nationwide surveillance study on neonatal and young infant sepsis due to Group B Streptococci (GBS) and Escherichia coli in Germany was conducted between 2009 and 2010. The aim of this study is to provide longitudinal epidemiological data on neonatal and young infant sepsis caused by GBS and $E$. coli to reevaluate existing data and to inform clinical decision-making. Every positive blood culture for GBS and E. coli within the first 90 days of life that occurred at our center from 2008 until 2018 was identified. The epidemiological, clinical, laboratory, and microbiological data of all affected patients were analyzed through retrospective chart review, along with the pathogen's antimicrobial susceptibility results. In total, 106 episodes of neonatal sepsis were described; $31 \%(n=33)$ being caused by GBS and $69 \%(n=73)$ by E. coli; $87 \%$ of GBS early-onset disease (EOD) cases did not receive intrapartum antibiotic prophylaxis (IAP). Contrary to general trends, the proportion of resistant $E$. coli isolates decreased for all tested antibiotics over time. Coincidentally, antenatal antibiotic use beyond IAP during that period decreased significantly in our center.

Conclusions: (1) Data at our center suggests at least a regional implementation gap in GBS screening and IAP. (2) The decline in the resistance rate of $E$. coli for all antimicrobial substances might indicate that the reduction of prenatal antibiotics use is beneficial and that neonatal antibiotic stewardship programs should include pregnant women as well.
\end{abstract}

Electronic supplementary material The online version of this article (https://doi.org/10.1007/s00431-020-03659-8 ) contains supplementary material, which is available to authorized users.

Maren Doenhardt

maren.doenhardt@tu-dresden.de

Barbara Seipolt

barbara.seipolt@uniklinikum-dresden.de

Lars Mense

lars.mense@uniklinikum-dresden.de

Jennifer Lucia Winkler

jenniferlucia.winkler@uniklinikum-dresden.de

Alexander Thürmer

alexander.thuermer@tu-dresden.de

Mario Rüdiger

mario.ruediger@uniklinikum-dresden.de
Reinhard Berner

reinhard.berner@uniklinikum-dresden.de

Jakob Armann

jakob.armann@uniklinikum-dresden.de

1 Department of Pediatrics, University Hospital and Medical Faculty Carl Gustav Carus, Technische Universität (TU) Dresden,

Fetscherstraße 74, D-01307 Dresden, Germany

2 Department of Gynecology and Obstetrics, University Hospital and Medical Faculty Carl Gustav Carus, Technische Universität (TU) Dresden, Fetscherstraße 74, D-01307 Dresden, Germany

3 Institute of Medical Microbiology and Hygiene, Medical Faculty Carl Gustav Carus, Technische Universität (TU) Dresden, Fetscherstraße 74, D-01307 Dresden, Germany 
What is Known:

- GBS screening and intrapartum antibiotic prophylaxis led to a 32\%-reduction in GBS disease in Germany with a 0.75 (92:122) ratio of early-onset disease to late-onset disease in 2009-2010.

- Prenatal antibiotic use might increase the risk of E. coli early-onset disease and antibiotic resistances.

What is New:

- The GBS early-onset disease rates were twice as high as those of late-onset disease, the ratio was 1.75 (21:12) in 2008-2018 at our institution. This suggests that there are at least regional implementation gaps in the antenatal GBS screening in Germany.

- We found a decline in E. coli resistance rates over time for all antimicrobial substances. Reduction in use of prenatal antibiotics might be an explanation.

Keywords Neonatal Sepsis · Group B Streptococcus $\cdot$ Escherichia coli $\cdot$ Intrapartum antibiotic prophylaxis (IAP) $\cdot$ Antibiotic resistance

$\begin{array}{ll}\text { Abbreviations } \\ \text { ASP } & \text { Antibiotic stewardship program } \\ \text { BPB } & \text { Bronchopulmonary dysplasia } \\ \text { CrP } & \text { C-reactive protein } \\ \text { E. coli } & \text { Escherichia coli } \\ \text { EOD } & \text { Early-onset disease } \\ \text { GBS } & \text { Group B Streptococcus } \\ \text { IAP } & \text { Intrapartum antibiotic prophylaxis } \\ \text { ICH } & \text { Intracerebral hemorrhage } \\ \text { IL-6 } & \text { Interleukin-6 } \\ \text { ITQ } & \text { Immature to total neutrophil ratio (quotient) } \\ \text { LOD } & \text { Late-onset disease } \\ \text { N } & \text { Number } \\ \text { PROM } & \text { Premature rupture of membranes } \\ \text { VLBW } & \text { Very low birth weight } \\ \text { WBC } & \text { White blood cell count }\end{array}$

\section{Introduction}

Neonatal sepsis is a major cause of mortality and morbidity in infants [26]. Escherichia coli (E. coli) and Group B Streptococci (GBS, Streptococcus agalactiae) are the most common etiologic pathogens [16]. Antenatal GBS screening and intrapartum antibiotic prophylaxis (IAP) during labor have been shown to significantly decrease early-onset disease (EOD) caused by GBS [15, 23]. However, there are concerns that IAP might lead to an increase in neonatal sepsis caused by non-GBS pathogens, particularly E. coli $[2,19]$. Germany has not yet adopted a universal GBS screening funded by the public health insurance, even though this screening has been recommended by periodicallyreviewed national guidelines since 2000 [1]. Currently, no data is available on how widespread physicians are implementing this screening and IAP. However, the worldwide systematic review of IAP policies for the prevention of GBS disease by Le Doare et al. estimated a 60\% coverage rate of IAP in Germany in 2017 [11].

It is important that physicians understand epidemiological changes in order to be able to perform informed clinical decision-making, especially regarding appropriate empirical antibiotic therapy. The German Neonatal Infection Surveillance Network (NeoKISS; "Krankenhaus-Infektions-SurveillanceSystem") provides valuable data regarding longitudinal epidemiology; however, it only focuses on very low birth weight (VLBW), $<1500 \mathrm{~g}$, premature infants [5]. A nationwide surveillance study on neonatal sepsis due to GBS and E. coli in Germany was last conducted between 2009 and 2010 [7, 23]. The aim of this retrospective data analysis is to update these results from 2010, describe the epidemiology, outcome, and bacterial resistance of neonatal infection due to GBS and $E$. coli over the past decade in a large German neonatal center.

\section{Material and methods}

\section{Clinical data collection}

Between January 2008 and December 2018, all patients with E. coli and GBS isolates from positive blood cultures within the first 90 days of life were identified at the Department of Pediatrics, University Hospital Dresden, TU Dresden, Germany. The detection of E. coli or GBS in blood cultures was the criterion for inclusion to the study. The epidemiological, clinical, and microbiological data of the infants and their mothers were collected through retrospective chart review.

Early-onset disease (EOD) was defined as infections occurring between the first and sixth day of life, infections occurring between the seventh and the 90th day of life were classified as late-onset disease (LOD).

Not every infant was born at our center, therefore not every infant's and mother's clinical history could be retrieved retrospectively. On this account some data is incomplete. Accordingly, not every of the 106 infant-mother-pairs offer complete data of antenatal microbiological swabs and use of IAP. IAP was considered adequate if there was documentation of at least 2 doses of penicillin $\mathrm{G}$ or ampicillin $>4 \mathrm{~h}$ before delivery.

However, for all infants weighing $<1500 \mathrm{~g}$ who were born at our institution from 2014 to 2018 , data on antenatal antibiotic administration in women with pending premature birth at 
our center was available. This data of very low birth weight (VLBW) infants was collected separately within the perinatal conference at our center.

\section{Microbiological examination}

Bacterial isolates from positive blood cultures (BACTEC, BD Diagnostics, Heidelberg, Germany) and screening swabs were identified based on colony morphology on Columbia blood agar using VITEK 2 (bioMérieux, Nürtingen, Germany), agglutination tests for B-hemolytic streptococci (Pastorex Strep Kit, BioRad, France), and, since 2011, MALDI-TOF MS (Bruker Daltonik, Bremen, Germany). Antimicrobial susceptibility testing was performed according to criteria of the European Committee on Antimicrobial Susceptibility Testing (EUCAST) of the European Society of Clinical Microbiology and Infectious Diseases (ESCMID), according the CLSI-standard (Clinical and Laboratory Standards Institute) [21]. Microbiological screening swabs were obtained per recommendation of the Commission for Hospital Hygiene and Infection Prevention at the Robert Koch- Institute in Germany (KRINKO). Ear swabs were taken from every newborn after birth. Throat and rectal swabs were obtained weekly for all patients.

\section{Laboratory}

White blood cell count (WBC), immature to total neutrophil ratio (ITQ), C-reactive protein (CrP), and Interleukin-6 (IL-6) were analyzed as indications of bacterial infection. WBC 5 to $21 \mathrm{GPt} / \mathrm{L}, \mathrm{CrP}<10 \mathrm{mg} / \mathrm{L}, \mathrm{IL}-6<150 \mathrm{pg} / \mathrm{mL}$, and ITQ $<0.2$ were considered typical values for healthy individuals.

\section{Statistical analyses}

Results are expressed as the median value (range) for continuous variables and $n(\%)$ for categorical variables for the statistical analysis. The calculated percentage values always reflect the available data for that specific variable (Table 1).The binomial test was used to determine the male to female ratio and the effects of continuous covariates with the KruskalWallis test. Fisher's Exact test was used to determine categorical variables for the statistical analysis. $p$ values $\leq 0.05$ were ascertained to be statistically significant.

\section{Results}

\section{Epidemiology}

A total of 106 episodes of blood culture proven neonatal and young infant sepsis were identified during the study period, with $31 \%(n=33)$ caused by GBS and $69 \%(n=73)$ by $E$. coli. The infection rate was higher for male $(n=61,58 \%)$ than female infants $(n=45,42 \% ; p=0.02)$. There was no significant difference found between the male/female ratio for GBS ( $m: f=20: 13$; $1.5)$ and $E$. coli $(41: 32 ; 1.3)$. However, the predominance of male infants could be detected only for EOD $(37: 22 ; 1.8 ; p=$ $0.02)$ and not for $\operatorname{LOD}(24: 23 ; 1.05 ; p=0.1)$ (Fig. 1a).

Annually, the ratio between $E$. coli and GBS neonatal sepsis ranged from 1:1 to 7:1, without any identifiable trend (Fig. 1b). Figure 2 shows the infant's age at the time of diagnosis for each case. Two thirds of GBS cases were EOD whereas E. coli was evenly distributed throughout EOD and LOD.

GBS blood stream infections were more common in full-term infants $(n=23,70 \%)$ than $E$. coli $(n=18,25 \% ; p=<0.001)$; even when analyzed for EOD and LOD separately, this did not change (EOD $\mathrm{p}=<0.001 /$ LOD $p=0.02$ ) (A1 Tables 1, 2, and 3).

The overall number of C-sections did not differ between GBS and $E$. coli. Focusing only on LOD, infants with $E$. coli infection $(n=16,59 \%)$, additional to the fact that they were more preterm $(p=0.02)$, were more often born via $\mathrm{C}$-section than infants with GBS infection $(n=1,10 \% ; p=0.01)$ (A1 Table 3$)$.

During routine microbiological screening swabs as recommended by the KRINKO, neonatal colonization with the pathogen causing invasive disease did not differ between GBS $(55 \%)$ and E. coli $(52 \%)$ at the time of infection onset. Approximately one-third of the infants were colonized with another pathogen than the one causing invasive disease (A1 Tables 1, 2, and 3).

\section{Outcome}

Regarding all EOD and LOD cases, there was no detectable difference between GBS $(n=2,6 \%)$ and $E$. coli $(n=6,8 \%)$ mortality. Significantly more GBS infected infants suffered from meningitis (GBS $n=9,27 \%$; E. coli $n=6,8 \% ; p=0.015)$. Specifically, LOD with GBS occurred with $58 \%(n=7)$ of meningitis cases, in contrast to $9 \%(n=3)$ for E. coli $(p=0.001)$ (A1 Table 3). Overall, complications like intracerebral hemorrhage (ICH) and bronchopulmonary dysplasia (BPD) affected more E. coli- than GBS-infected children $(p(\mathrm{ICH})=0.01 ; p(\mathrm{BPD})=0.006)($ Table 1$)$.

\section{Biomarkers}

Laboratory studies at disease onset and after 36-72 $\mathrm{h}$ were analyzed. The data for WBC, ITQ, CrP, and IL-6 is summarized in Table 1 (A1 Tables 1, 2, 3, and 4). At the time of infection, IL-6 and ITQ were generally the most sensitive markers; however, in subsequential labs, $\mathrm{CrP}$ was the most sensitive marker. Initially, $8 \%$ of infants with GBS disease and $17 \%$ of infants with $E$. coli disease showed no elevated blood markers indicating a bacterial infection. On repeated evaluation, $8 \%$ of GBS and $14 \%$ of $E$. coli infections continued to lack abnormalities in laboratory studies despite proven 
Table 1 Clinical characteristics of neonatal sepsis: Group B Streptococcus (GBS) vs. Escherichia coli (E. coli)

\begin{tabular}{|c|c|c|c|c|c|c|c|}
\hline \multirow[t]{2}{*}{ All (EOD + LOD) $(n=106)$} & & & \multicolumn{2}{|l|}{$\operatorname{GBS}(n=33)$} & \multicolumn{3}{|l|}{ E. $\operatorname{coli}(n=73)$} \\
\hline & & & Values & NA & Values & NA & $p$ \\
\hline EOD(DOL1-6):LOD(DOL7-90) & ratio & (ratio) & $21: 12(1.75)$ & 0 & $38: 35(1.1)$ & 0 & NS \\
\hline Male:female & ratio & (ratio) & $20: 13(1.5)$ & 0 & $41: 32(1.3)$ & 0 & NS \\
\hline Age at time of onset (days) & median & (range) & $2(1-50)$ & 0 & $6(1-87)$ & 0 & NS \\
\hline Gestational Age (weeks) & median & (range) & $38(26-41)$ & 0 & $31(23-41)$ & 0 & 0.002 \\
\hline Preterm birth $(<37 \mathrm{GA})$ & $n$ & $(\%)$ & $10(30 \%)$ & 0 & $55(75 \%)$ & 0 & $<0.001$ \\
\hline Extreme preterm birth $(<28 \mathrm{GA})$ & $n$ & $(\%)$ & $5(15 \%)$ & 0 & $23(32 \%)$ & 0 & NS \\
\hline Birthweight $(\mathrm{g})$ & median & (range) & $3210(890-4370)$ & 2 & $1430(430-4660)$ & 7 & NS \\
\hline Low Birthweight (<2500 g) & $n$ & $(\%)$ & $11(33 \%)$ & 0 & $55(75 \%)$ & 0 & $<0.001$ \\
\hline Very low Birthweight $(<1500 \mathrm{~g})$ & $n$ & $(\%)$ & $5(15 \%)$ & 0 & $35(48 \%)$ & 0 & 0.001 \\
\hline Extremely low Birthweight $(<1000 \mathrm{~g})$ & $n$ & $(\%)$ & $3(9 \%)$ & 0 & $23(32 \%)$ & 0 & 0.01 \\
\hline C-section & $n$ & $(\%)$ & $11(35 \%)$ & 2 & $38(58 \%)$ & 8 & NS \\
\hline Multiple gestation & $n$ & $(\%)$ & $4(12 \%)$ & 0 & $10(14 \%)$ & 0 & NS \\
\hline Neonatal colonization at time of infection & $n$ & $(\%)$ & $18(55 \%)$ & 0 & $38(52 \%)$ & 0 & NS \\
\hline Mortality & $n$ & $(\%)$ & $2(6 \%)$ & 0 & $6(8 \%)$ & 0 & NS \\
\hline Meningitis & $n$ & $(\%)$ & $9(27 \%)$ & 0 & $6(8 \%)$ & 0 & 0.015 \\
\hline $\mathrm{ICH}$ & $n$ & $(\%)$ & $4(12 \%)$ & 0 & $27(37 \%)$ & 0 & 0.01 \\
\hline NEC & $n$ & $(\%)$ & $0(0 \%)$ & 0 & $6(8 \%)$ & 0 & NS \\
\hline BPD & $n$ & $(\%)$ & $2(6 \%)$ & 0 & $22(30 \%)$ & 0 & 0.006 \\
\hline \multicolumn{8}{|l|}{ Initial labs } \\
\hline $\mathrm{WBC}<5$ or $>21 \mathrm{GPt} / \mathrm{L}$ & $n$ & $(\%)$ & $14(42 \%)$ & 0 & $26(36 \%)$ & 0 & NS \\
\hline ITQ $>0.2$ & $n$ & $(\%)$ & $23(74 \%)$ & 2 & $41(64 \%)$ & 9 & NS \\
\hline $\mathrm{CrP}>10 \mathrm{mg} / \mathrm{L}$ & $n$ & $(\%)$ & $16(48 \%)$ & 0 & $39(55 \%)$ & 2 & NS \\
\hline $\mathrm{IL}-6>1000 \mathrm{pg} / \mathrm{mL}$ & $n$ & $(\%)$ & $21(81 \%)$ & 7 & $30(63 \%)$ & 25 & NS \\
\hline All labs normal * & $n$ & $(\%)$ & $2(8 \%)$ & 7 & $8(17 \%)$ & 25 & NS \\
\hline \multicolumn{8}{|l|}{ Labs $36-72 \mathrm{~h}$} \\
\hline $\mathrm{WBC}<5$ or $>21 \mathrm{GPt} / \mathrm{L}$ & $n$ & $(\%)$ & $9(33 \%)$ & 6 & $18(33 \%)$ & 19 & NS \\
\hline ITQ $>0.2$ & $n$ & $(\%)$ & $4(17 \%)$ & 10 & $18(37 \%)$ & 24 & NS \\
\hline $\mathrm{CrP}>10 \mathrm{mg} / \mathrm{L}$ & $n$ & $(\%)$ & $19(76 \%)$ & 8 & $38(78 \%)$ & 24 & NS \\
\hline All labs normal $* *$ & $n$ & $(\%)$ & $2(8 \%)$ & 8 & $7(14 \%)$ & 24 & NS \\
\hline Maternal Age & median & (range) & $30(17-41)$ & 1 & $20(20-43)$ & 2 & NS \\
\hline \multirow[t]{2}{*}{ Only EOD $(n=59)$} & & & $\operatorname{GBS}(n=21)$ & & E. $\operatorname{coli}(n=38)$ & & \\
\hline & & & Values & NA & Values & NA & $p$ \\
\hline Maternal $\mathrm{WBC}<4$ or $>11 \mathrm{GPt} / \mathrm{L}$ at delivery & $n$ & $(\%)$ & $11(92 \%)$ & 9 & $20(69 \%)$ & 9 & NS \\
\hline Maternal $\mathrm{CrP}>10 \mathrm{mg} / \mathrm{L}$ at delivery & $n$ & $(\%)$ & $7(88 \%)$ & 13 & $12(43 \%)$ & 10 & 0.044 \\
\hline Amniotic swab same pathogen & $n$ & $(\%)$ & $7(100 \%)$ & 14 & $21(81 \%)$ & 12 & NS \\
\hline Vaginal colonization same pathogen & $n$ & $(\%)$ & $8(80 \%)$ & 11 & $12(35 \%)$ & 4 & 0.03 \\
\hline Rupture of membranes $>18 \mathrm{~h}$ & $n$ & $(\%)$ & $5(25 \%)$ & 1 & $22(59 \%)$ & 1 & 0.03 \\
\hline IAP administration & $n$ & $(\%)$ & $2(13 \%)$ & 5 & $27(77 \%)$ & 3 & $<0.001$ \\
\hline Antibiotic administration PROM & $n$ & $(\%)$ & $2(13 \%)$ & 5 & $27(77 \%)$ & 3 & $<0.001$ \\
\hline
\end{tabular}

Statistical analyses was formed with binomial test for male:female ratio, Kruskal-Wallis test for continuous covariates, and Fisher's exact tests for categorical variables. $p$ values of $\leq 0.05$ were deemed to be significant.

$E O D$ Early-onset disease (day of life 1-6d), LOD Late-onset disease (day of life 7-90d), GA Gestational age, NA Number of cases for which data were not available, $N S$ Not significant $(p>0.05)$, ICH Intracerebral hemorrhage, $N E C$ Necrotizing enterocolitis, $B P D$ Bronchopulmonary dysplasia, WBC White blood cells, ITQ immature/total quotient, $C r P$ C-reactive protein, IAP Intrapartum antibiotic prophylaxis, $P R O M$ Premature rupture of membranes.

* WBC 5-21, ITQ $<0.2$, CrP $<10$, IL-6 $<150$

** WBC 5-21, ITQ $<0.2, \mathrm{CrP}<10$ 
Fig. 1 Ratios. a Male: female ratio in all cases $(p=0.02)$, earlyonset disease $(p=0.02)$, and lateonset disease $(p=0.11)$. b GBS: E. coli ratio over 10 -year study period (2008-2018)

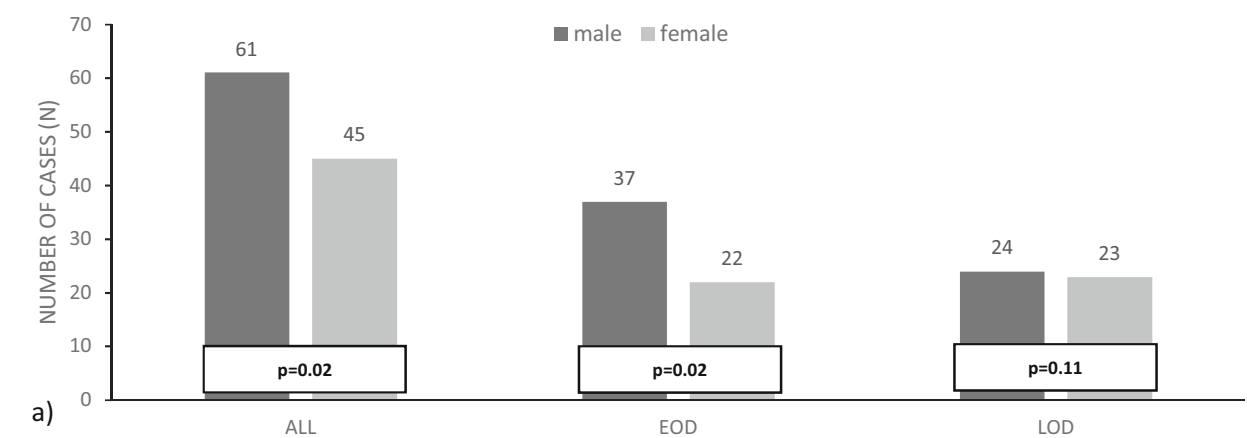

a)

ALL

- GBS E. coli

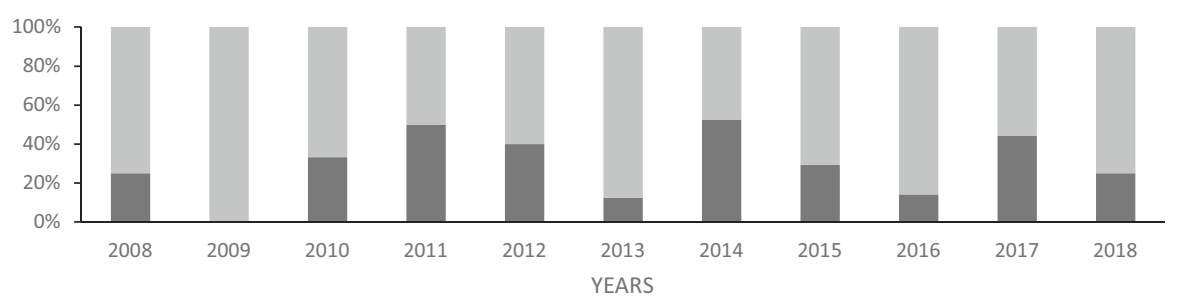

bacteremia. Only $17 \%$ (10 of 59) of all EOD (2 of $21 \mathrm{GBS}$ EOD, 8 of 38 E. coli EOD) had IL-6 levels $<150 \mathrm{pg} / \mathrm{mL} ; 90 \%$ $(9 / 10)$ of these infants were preterm. Only in GBS LOD, all patients presented at least one abnormal blood marker.

There were no statistically significant differences between $E$. coli and GBS infection regarding any of the analyzed biomarkers. Between first and second blood samples, however, the increase in CrP as well as the decrease in ITQ were significant $(p(\mathrm{CrP})=0.0005$ and $p(\mathrm{ITQ})=0.0001)(\mathrm{A} 2$ Table 5$)$.

\section{Maternal factors}

The results of maternal laboratory tests were analyzed for EOD cases. The proportion of increased $\mathrm{CrP}$ at delivery (>10 mg/L) was significantly higher in women giving birth to children with GBS $(n=7,80 \%)$ compared with children with $E$. coli sepsis $(n=12,43 \% ; p=0.044)$.
Prepartal vaginal swabs and amniotic membrane swabs taken at time of the C-section were compared with the infants' blood culture results. Results of prepartal vaginal or amniotic swabs were not available for all women. Amniotic swabs and vaginal swabs were available for nearly every $\mathrm{C}$-section that was performed at our center. Regarding all women, prepartal vaginal swabs, that were taken a few days or hours before delivery, were available in 67 of 106 cases. Focusing only on EOD, prepartal vaginal swabs were available in 10 of 21 GBS and 34 of 38 E. coli cases (Table 1). In EOD cases, $80 \%$ of mothers (whose children subsequently developed GBS disease) were vaginally colonized with GBS before birth whereas in cases of $E$. coli, only $35 \%$ were vaginally colonized $(p=0.03)$. In $\mathrm{C}$-sectioned women, amniotic swabs demonstrated detection rates of $100 \%$ for GBS and $81 \%$ for $E$. coli with regard to diseased infants.

Only two infants (13\% of GBS EOD cases), both preterm, developed early onset GBS disease despite intrapartum
Fig. 2 Age at time of diagnosis (day/week of life)

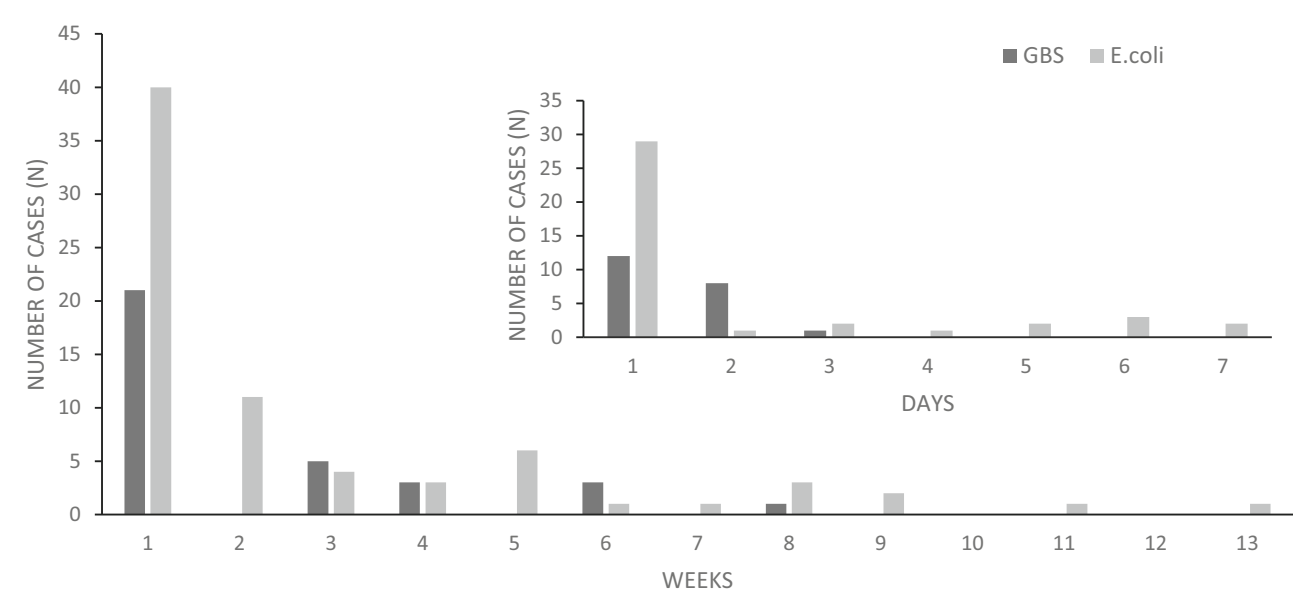


Fig. 3 Antimicrobial resistance rate of a E. coli over 10-year study period (2008-2018), b E. coli overall, and $\mathbf{c}$ GBS overall

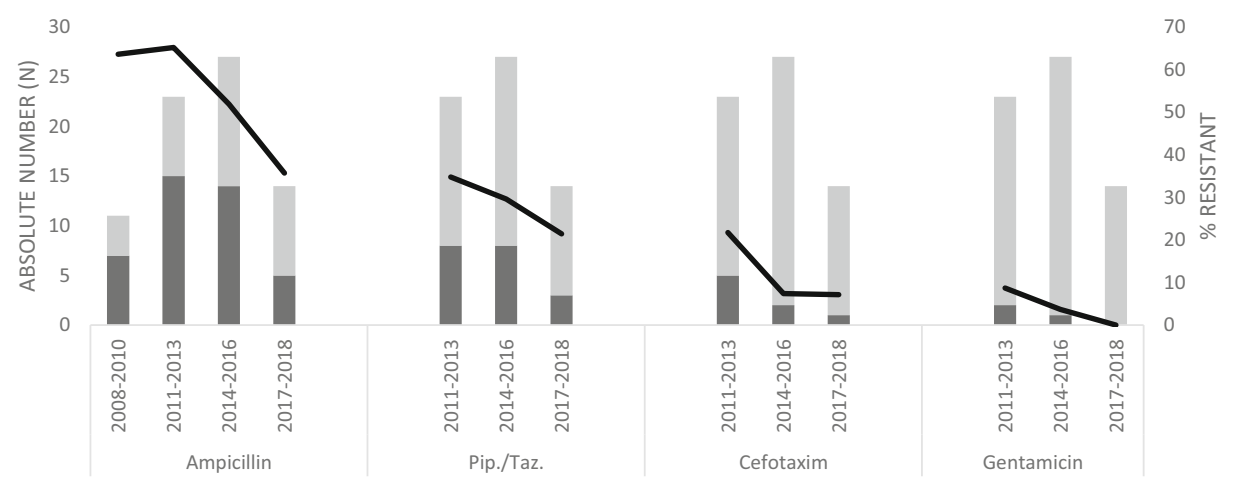

a)

N resistant $\quad$ N susceptible $\quad$ \% resistant

b)

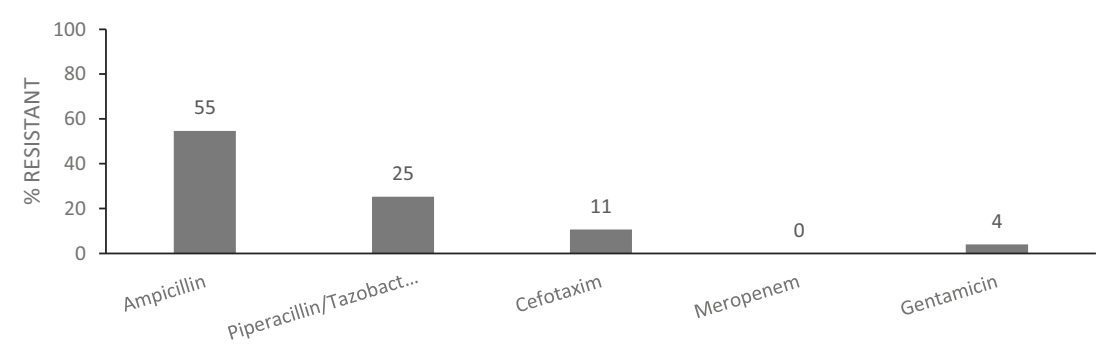

c)

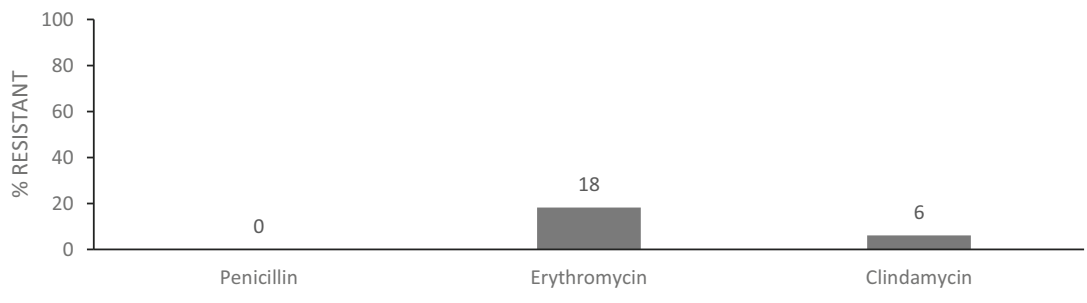

prophylaxis. The rate of premature rupture of membranes $(\mathrm{PROM})>18 \mathrm{~h}$ was significantly higher in EOD E. coli $(n=21,59 \%)$ than EOD GBS cases $(n=5,25 \%)(p=0.03)$. Antibiotic administration for PROM was significantly more frequent in mothers whose children developed $E$. coli $\mathrm{EOD}$ $(n=20,57 \%)$ compared with GBS $(n=2 ; 13 \% ; p=0.001)$ (Table 1; A1 Table 2).

\section{Antimicrobial resistance rates}

All GBS isolates were susceptible to penicillin, $6 \%$ were resistant to clindamycin, and $18 \%$ were resistant to erythromycin (Fig. 3c).

The proportion of resistant $E$. coli isolates decreased during the 10-year period for all tested antibiotics. Ampicillin resistance decreased from 64 to $36 \%(p=0.11)$, piperacillintazobactam resistance from 35 to $21 \%(p=0.47)$, cefotaxime resistance from 21 to $7 \%(p=0.37)$, and gentamicin resistance from 9 to $0 \%(p=0.51)$. Overall $55 \%$ of $E$. coli isolates were resistant to ampicillin, $25 \%$ to piperacillin-tazobactam, $11 \%$ to cefotaxime, and $4 \%$ to gentamicin. All isolates were susceptible to meropenem (Fig. 3a, b).

From 2014 to 2018 , overall antenatal antibiotic use in women with a pending premature birth decreased (52 vs. $33 \%, p=0.007$ ), with significantly reduced rates of carbapenems and cephalosporins (Fig. 4).

\section{Discussion}

At our center, GBS caused sepsis predominately in full-term neonates whereas $E$. coli caused disease mainly in preterm infants. These results are consistent with the existing literature [16]. The 1:2 infection rate of GBS to $E$. coli is contrary to the 2:1 infection rate found in a nationwide surveillance study in Germany in 2009-2010 [10]. This can be explained by an overrepresentation of premature infants in the selection sample of our tertiary perinatal center. 
Fig. 4 Antenatal antibiotic administration in women with a pending premature birth, regarding all premature infants (weighing $<1500 \mathrm{~g}$ ) born at our institution from 2014 to 2018
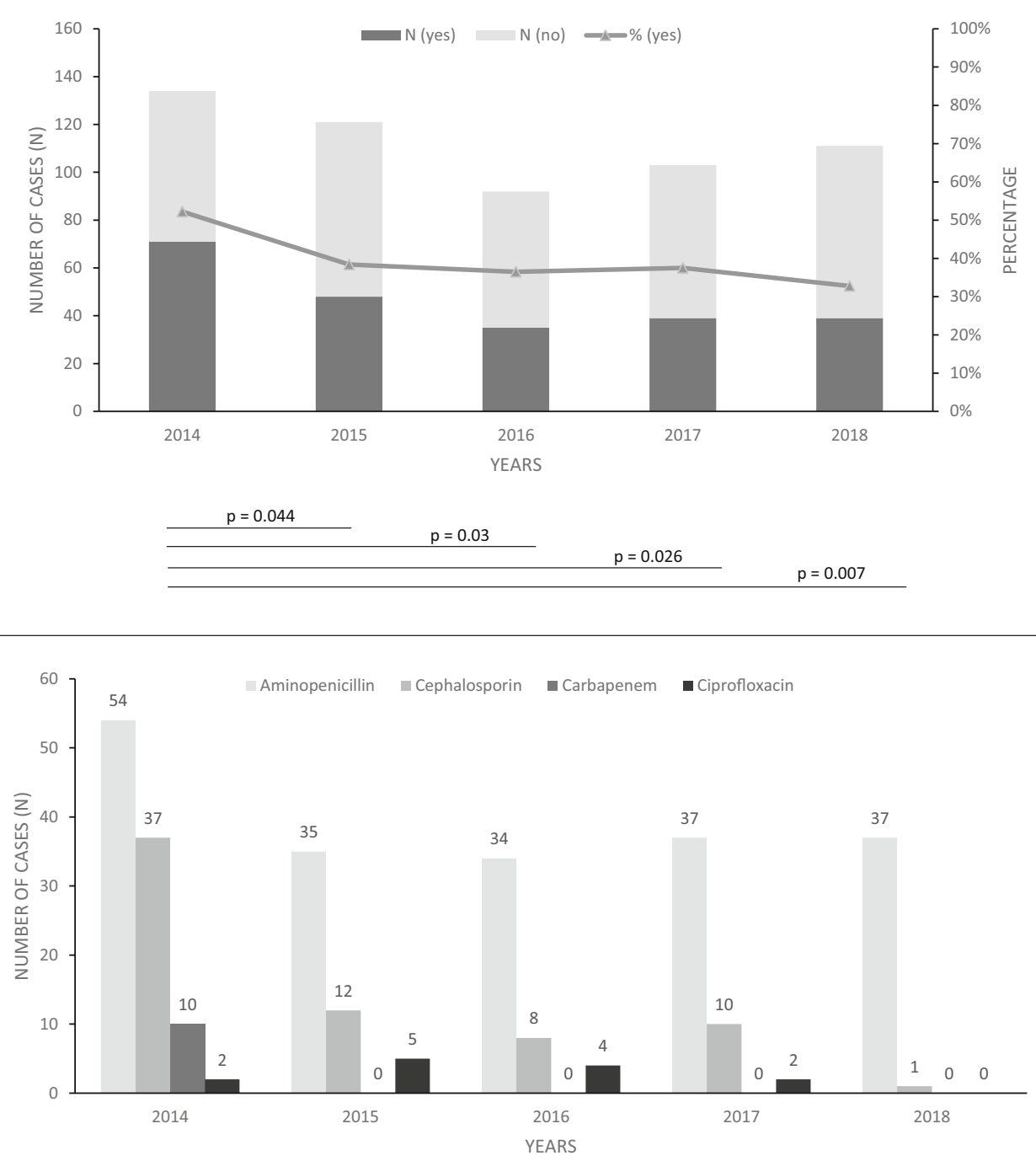

The observed mortality from GBS disease in $6 \%$ of patients in our study is consistent with previous reports [6]. The E. coli mortality rate in our study was significantly lower than that found in previous studies $[13,16]$. Nevertheless, $75 \%$ of infants with $E$. coli sepsis were preterm, and circa $50 \%$ were below $1500 \mathrm{~g}$ at birth and, therefore, critically vulnerable.

Consistent with current literature, $60 \%$ of patients with GBS LOD in our study had meningitis, however, also 8 $10 \%$ of infants with GBS EOD or E. coli suffered from meningitis [8]. Given the therapeutic and prognostic consequences, this warrants evaluation of all bacteremic infants for meningitis regardless of onset of disease.

The higher incidence of ICH and BPD in E. coli sepsis most probably is due to the higher proportion of premature infants with $E$. coli sepsis. This difference is no longer statistical significant after stratifying for gestational age (A1 Table 4).

We confirmed the reasonable high sensitivity of ITQ and IL-6 at the time of diagnosis, indicating that biomarkers indeed may help to rule out neonatal and young infant sepsis and thereby help to reduce the well-described antibiotic overuse in this age group [17].

However, there was no significant, detectable increase in CrP levels before 36-72 $\mathrm{h}$ after disease-onset. [18]. Interestingly, even after subsequent evaluation, $8-14 \%$ of infants with proven bacteremia did not have any abnormal biomarkers, which emphasizes the importance of blood culture diagnostics in suspected bloodstream infection.

Maternal biomarkers seem to be pathogen-dependent, with higher positive rates in GBS than E. coli EOD. This suggests that negative laboratory studies should never be seen to definitely rule out sepsis, in particular not in preterm infants with a high risk of $E$. coli sepsis.

Universal antenatal GBS screening and IAP) in the United States led to a six-fold decrease in the incidence of EOD, and currently, approximately equal rates of EOD and LOD [15]. Wicker et al. described the development of GBS disease after publication of the guidelines for culture-based screening for GBS colonization in Germany. A 32\% reduction in GBS disease incidence was detected. The ratio of early-onset disease 
to late-onset disease reversed from 1.52 (206:136) in 20012003 to 0.75 (92:122) in 2009-2010 [23]. In contrast, our study shows a ratio of 1.75 (21:12) with GBS EOD rates that are twice as high as those for LOD. This suggests that there are at least regional implementation gaps in the antenatal GBS screening in Germany. A universal screening program would therefore lead to a further reduction in infant morbidity and mortality from GBS. The fact that only two infants with GBS EOD received the IAP further substantiates this point. The most likely explanation for the IAP failure in those children is the fact that they were born very premature at 27 weeks gestational age making them more susceptible for infections.

The high burden of $E$. coli disease in premature infants highlights the need for effective prevention. Administration of broad-spectrum antibiotics based on maternal microbiological sampling has been suggested [12, 24, 25]. However, in contrast to GBS, E. coli can only be detected in one-third of the respective EOD cases in prepartal vaginal swabs, making it difficult to identify patients at risk for $E$. coli sepsis. More importantly, there is data that suggest that antenatal antibiotic use might increase the risk of E. coli EOD [22]. The high prevalence of $E$. coli in EOD infants that were prenatally exposed to antibiotics in our study substantiates these findings and calls this approach into question.

Antimicrobial resistance rates for GBS were overall low and consistent with results from a previous nationwide surveillance study in Germany in 2009-2010 [3, 7, 23]. Resistance rates for E. coli, on the other hand, were cumulatively higher than those reported in this previous study, especially for ampicillin and third-generation cephalosporins. In addition, we found a decline in resistance rates over time for all antimicrobial substances in our study, and notably for ampicillin. An explanation might be the reduction in use of prenatal antibiotics in our obstetrics and gynecology department, especially broadspectrum antibiotics such as cephalosporins and carbapenems. This coincides with the decrease in resistant $E$. coli in neonatal sepsis, contrary to the previously published findings; Dona et al. as well reported about a decrease in extended spectrum beta-lactamase (ESBL) producers E. coli $[3,4,9,14,20]$. Nevertheless, these results are due to the implementation of pediatric antibiotic stewardship programs (ASP). Our data points to the importance of including pregnant women in neonatal ASPs as well.

Our study is limited by its retrospective design leading to incomplete data especially in mothers who were not treated at our institution. In addition, we provide regional data only from a single center that might not necessarily reflect the situation in other parts of Germany accurately. We feel confident though that our findings warrant additional studies in Germany in regard to the nationwide implementation of screening and prophylaxis and the development of resistance rates.

\section{Conclusion}

Given the documented regional implementation gaps of the risk-based GBS screening further studies are needed to evaluate the nationwide implementation of current guidelines. A universal GBS screening could reduce infant mortality and morbidity in Germany.

Antenatal long-term administration of broad-spectrum antibiotics to women with pending premature birth might increase the incidence of $E$. coli $\mathrm{EOD}$ and leads to antimicrobial resistance. Rational antenatal antibiotic prescription might help reduce the problem of multi-drug resistance in neonatal and young infant sepsis. It is important that neonatal ASPs include pregnant women as well.

Authors' contributions MD: Material preparation; Data collection; Data analysis; First and second draft of the manuscript; Approval of the final manuscript BS: Critical revision of the article for important intellectual content (Esp. Neonatology); Approval of the final manuscript LM: Critical revision of the article for important intellectual content (Esp. Neonatology); Approval of the final manuscript JW: Critical revision of the article for important intellectual content (Esp. Gynecology and Obstetrics); Approval of the final manuscript AT: Mircobiological data collection; critical revision of the article for important intellectual content (Esp. Clinical Microbiology); Approval of the final manuscript MR: Critical revision of the article for important intellectual content (Esp. Neonatology); Approval of the final manuscript RB: Critical revision of the article for important intellectual content (Esp. Pediatric Infectious Diseases); Approval of the final manuscript JA: Study conception and design; Data analysis; First and second draft of the manuscript; Approval of the final manuscript.

Funding Information Open Access funding provided by Projekt DEAL.

\section{Compliance with ethical standards}

Conflict of interest The authors declare that they have no conflict of interest.

Ethical approval This article does not contain any studies with human participants or animals performed by any of the authors.

Informed consent Not necessary according to the German Ethics Committee ("Ethikkommission at Technical University (TU) Dresden"), reference number: AZ: EK 313082018; [Technische Universität Dresden Ethikkommission an der TU Dresden, Fetscherstrasse 74, 01307 Dresden, +49,351,458-2992]

Open Access This article is licensed under a Creative Commons Attribution 4.0 International License, which permits use, sharing, adaptation, distribution and reproduction in any medium or format, as long as you give appropriate credit to the original author(s) and the source, provide a link to the Creative Commons licence, and indicate if changes were made. The images or other third party material in this article are included in the article's Creative Commons licence, unless indicated otherwise in a credit line to the material. If material is not included in the article's Creative Commons licence and your intended use is not permitted by statutory regulation or exceeds the permitted use, you will need to obtain permission directly from the copyright holder. To view a copy of this licence, visit http://creativecommons.org/licenses/by/4.0/. 


\section{References}

1. Arbeitsgemeinschaft der Wissenschaftlichen Medizinischen Fachgesellschaften (AWMF) -Ständige Kommission Leitlinien (2016) S2k-Leitlinie 024-020 "Prophylaxe der Neugeborenensepsis - frühe Form - durch Streptokokken der Gruppe B".Available at https://www. awmf.org/uploads/tx_szleitlinien/024-0201_S2k_Prophylaxe Neugeborenensepsis_Streptokokken_2016-04.pdf. Accessed 12 Jun 2019

2. Bizzarro MJ, Dembry LM, Baltimore RS, Gallagher PG (2008) Changing patterns in neonatal Escherichia coli sepsis and ampicillin resistance in the era of intrapartum antibiotic prophylaxis. Pediatrics 121(4):689-696. https://doi.org/10.1542/peds.2007-2171

3. Bundesamt für Verbraucherschutz und Lebensmittelsicherheit, Paul-Ehrlich-Gesellschaft für Chemotherapie e.V. (ed) (2016) GERMAP 2015. Antibiotika-Resistenz und -Verbauch; Bericht über den Antibiotikaverbrauch und die Verbreitung von Antibiotikaresistenzen in der Human- und Veterinärmedizin in Deutschland, 4th edn. Antiinfectives Intelligence, Rheinbach

4. Donà $\mathrm{D}$, Barbieri E, Daverio $\mathrm{M}$, Lundin R, Giaquinto $\mathrm{C}$, Zaoutis T, Sharland M (2020) Implementation and impact of pediatric antimicrobial stewardship programs: a systematic scoping review. Antimicrob Resist Infect Control 9:3. https://doi.org/10.1186/s13756-019-0659-3

5. Gastmeier P, Sohr D, Schwab F, Behnke M, Zuschneid I, Brandt C, Dettenkofer M, Chaberny IF, Rüden H, Geffers C (2008) Ten years of KISS: the most important requirements for success. J Hosp Infect 70(SUPPL. 1):11-16. https://doi.org/10.1016/S0195-6701(08)60005-5

6. Hamada S, Vearncombe M, McGeer A, Shah PS (2008) Neonatal group B streptococcal disease: incidence, presentation, and mortality. J Matern Fetal Neonatal Med 21(1):53-57. https://doi.org/10. 1080/14767050701787474

7. Heideking M, Lander F, Hufnagel M, Pfeifer Y, Wicker E, Krause G, Berner R (2013) Antibiotic susceptibility profiles of neonatal invasive isolates of Escherichia coli from a 2-year nationwide surveillance study in Germany, 2009-2010. Eur J Clin Microbiol Infect Dis 32(9):1221-1223. https://doi.org/10.1007/s10096-013-1871-3

8. Joubrel C, Tazi A, Six A, Dmytruk N, Touak G, Bidet P, Raymond J, Trieu Cuot P, Fouet A, Kerneis S, Poyart C (2015) Group B streptococcus neonatal invasive infections, France 2007-2012. Clin Microbiol Infect 21(10):910-916. https://doi.org/10.1016/j.cmi.2015.05.039

9. Lagacé-Wiens PRS, Adam HJ, Low DE, Blondeau JM, Baxter MR, Denisuik AJ, Nichol KA, Walkty A, Karlowsky JA, Mulvey MR, Hoban DJ, Zhanel GG, Canadian Antimicrobial Resistance Alliance (2013) Trends in antibiotic resistance over time among pathogens from Canadian hospitals: results of the CANWARD study 2007-11. J Antimicrob Chemother 68(Suppl 1). https://doi. org/10.1093/jac/dkt023

10. Lander F, Heinrich B, Hufnagel M, Flügge K, Kries RV, Berner R (2010) Epidemiologie invasiver Infektionen durch Escherichia coli bei Neugeborenen und jungen Säuglingen in Deutschland Aktuelle Ergebnisse der laufenden ESPED-Studie. Klin Padiatr 222(S 01). doi:https://doi.org/10.1055/s-0030-1261467

11. Le Doare K, O'Driscoll M, Turner K, Seedat F, Russell NJ, Seale AC, Heath PT, Lawn JE, Baker CJ, Bartlett L, Cutland C, Gravett MG, Ip M, Madhi SA, Rubens CE, Saha SK, Schrag S, SobanjoTer Meulen A, Vekemans J, Kampmann B (2017) Intrapartum antibiotic chemoprophylaxis policies for the prevention of group B streptococcal disease worldwide: systematic review. Clin Infect Dis 65(Suppl 2):S143-S151. https://doi.org/10.1093/cid/cix654

12. Lee J, Romero R, Kim SM, Chaemsaithong P, Yoon BH (2016) A new antibiotic regimen treats and prevents intra-amniotic inflammation/infection in patients with preterm PROM. J Matern Fetal Neonatal Med 29(17):2727-2737. https://doi.org/10.3109/ 14767058.2015.1103729

13. Mayor-Lynn K, González-Quintero VH, O'Sullivan MJ, Hartstein AI, Roger S, Tamayo M (2005) Comparison of early-onset neonatal sepsis caused by Escherichia coli and group B Streptococcus. Am J Obstet Gynecol 192(5 SPEC. ISS):1437-1439. https://doi.org/10. 1016/j.ajog.2004.12.031

14. Mendoza-Palomar N, Balasch-Carulla M, González-Di Lauro S, Céspedes MC, Andreu A, Frick MA, Linde MÁ, Soler-Palacin P (2017) Escherichia coli early-onset sepsis: trends over two decades. Eur J Pediatr 176(9):1227-1234. https://doi.org/10.1007/s00431017-2975-Z

15. Nanduri SA, Petit S, Smelser C, Apostol M, Alden NB, Harrison LH, Lynfield R, Vagnone PS, Burzlaff K, Spina NL, Dufort EM, Schaffner WS, Thomas AR, Farley MM, Jain JH, Pondo T, McGee L, Beall BW, Schrag SJ (2019) Epidemiology of invasive earlyonset and late-onset group B streptococcal disease in the United States, 2006 to 2015: multistate laboratory and population-based surveillance. JAMA Pediatr 173:224-233. https://doi.org/10.1001/ jamapediatrics.2018.4826

16. Schrag SJ, Farley MM, Petit S, Reingold A, Weston EJ, Pondo T, Jain JH, Lynfield R (2016) Epidemiology of invasive early-onset neonatal sepsis, 2005 to 2014. Pediatrics 138(6):e20162013. https:// doi.org/10.1542/peds.2016-2013

17. Schulman J, Dimand RJ, Lee HC, Duenas GV, Bennett MV, Gould JB (2015) Neonatal intensive care unit antibiotic use. Pediatrics 135(5):826-833. https://doi.org/10.1542/peds.2014-3409

18. Sharma D, Farahbakhsh N, Shastri S, Sharma P (2018) Biomarkers for diagnosis of neonatal sepsis: a literature review. J Matern Fetal Neonatal Med 31(12):1646-1659. https://doi.org/10.1080/ 14767058.2017.1322060

19. Stoll BJ, Hansen N, Fanaroff AA, Wright LL, Carlo WA, Ehrenkranz RA, Lemons JA, Donovan EF, Stark AR, Tyson JE, Oh W, Bauer CR, Korones SB, Shankaran S, Laptook AR, Stevenson DK, Papile L-A, Poole WK (2002) Changes in pathogens causing early-onset sepsis in very-low-birth-weight infants. N Engl J Med 347(4):240-247. https:// doi.org/10.1056/NEJMoa012657

20. Tadesse DA, Zhao S, Tong E, Ayers S, Singh A, Bartholomew MJ, McDermott PF (2012) Antimicrobial drug resistance in Escherichia coli from humans and food animals, United States, 1950-2002. Emerg Infect Dis 18(5):741-749. https://doi.org/10.3201/eid1805.111153

21. The European Committee on Antimicrobial Susceptibility Testing (2019) Breakpoint tables for interpretation of MICs and zone diameters. Available at: http://www.eucast.org/fileadmin/src/media/PDFs/ EUCAST_files/Breakpoint_tables/v_9.0_Breakpoint_Tables.pdf.

22. Tsai C-H, Chen Y-Y, Wang K-G, Chen C-Y, Chen C-P (2012) Characteristics of early-onset neonatal sepsis caused by Escherichia coli. Taiwan J Obstet Gynecol 51(1):26-30. https:// doi.org/10.1016/j.tjog.2012.01.006

23. Wicker E, Lander F, Weidemann F, Hufnagel M, Berner R, Krause G (2019) Group B streptococci: declining incidence in infants in Germany. Pediatr Infect Dis J 38(5):516-519. https://doi.org/10. 1097/INF.0000000000002115

24. Wolf MF, Miron D, Peleg D, Rechnitzer H, Portnov I, Salim R, Keness Y, Reich D, Ami MB, Peretz A, Koshnir A, Shachar IB (2015) Reconsidering the current preterm premature rupture of membranes antibiotic prophylactic protocol. Am J Perinatol 32(13):1247-1250. https://doi.org/10.1055/s-0035-1552935

25. Yoon BH, Romero R, Park JY, Oh KJ, Lee J, Conde-Agudelo A, Hong J-S (2019) Antibiotic administration can eradicate intraamniotic infection or intra-amniotic inflammation in a subset of patients with preterm labor and intact membranes. Am J Obstet Gynecol 221: 142.e1-142.e22. https://doi.org/10.1016/j.ajog.2019.03.018

26. Zea-Vera A, Ochoa TJ (2015) Challenges in the diagnosis and management of neonatal sepsis. J Trop Pediatr 61(1):1-13. https://doi.org/10.1093/tropej/fmu079

Publisher's note Springer Nature remains neutral with regard to jurisdictional claims in published maps and institutional affiliations. 